\title{
Assessing Depression Symptoms in Those with Insomnia: An Examination of the Beck Depression Inventory Second Edition (BDI-II)
}

\section{Colleen E. Carney}

Ryerson University

\section{Christi UImer}

Durham VA Medical Center

\section{Jack D. Edinger}

Duke University Medical Center

\section{Andrew D. Krystal}

Duke University Medical Center

\section{Faye Knauss}

Duke University Medical Center

digital.library.ryerson.ca/object/332

Please Cite:

Carney, C. E., Ulmer, C., Edinger, J. D., Krystal, A. D., \& Knauss, F. (2009).

Assessing depression symptoms in those with insomnia: An examination of the beck depression inventory second edition (BDI-II). Journal of Psychiatric Research, 43(5), 576-582.

doi:10.1016/j.jpsychires.2008.09.002

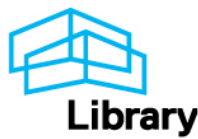




\title{
Assessing depression symptoms in those with insomnia: An examination of the Beck Depression Inventory Second Edition (BDI-II)
}

\author{
Colleen E. Carney, PhD ${ }^{1}$, Christi Ulmer, $\mathrm{PhD}^{3}$, Jack D. Edinger, $\mathrm{PhD}^{2,3}$, Andrew D. Krystal, \\ $\mathbf{M D}^{2}$, and Faye Knauss, PsyD $^{2}$ \\ 1 Ryerson University, Toronto, Canada
}

2 Duke University Medical Center, Durham, NC

3 Durham VA Medical Center, NC

\begin{abstract}
Background-Due to concerns about overlapping symptomatology between medical conditions and depression, the validity of the Beck Depression Inventory (BDI-II) has been assessed in various medical populations. Although Major Depressive Disorder (MDD) and Primary Insomnia (PI) share some daytime symptoms, the BDI-II has not been evaluated for use with insomnia patients.
\end{abstract}

Method-Participants $(\mathrm{N}=140)$ were screened for the presence of insomnia using the Duke Structured Clinical Interview for Sleep Disorders (DSISD), and evaluated for diagnosis of MDD using the Structured Clinical Interview for DSM-IV-TR (SCID). Participants' mean BDI-II item responses were compared across two groups [insomnia with or without MDD) using multivariate analysis of variance (MANOVA), and the accuracy rates of suggested clinical cutoffs for the BDIII were evaluated using a Receiver Operating Characteristic (ROC) curve analysis.

Results-The insomnia with depression group had significantly higher scores on several items; however, the groups did not differ on insomnia, fatigue, concentration problems, irritability, libido, increased appetite, and thoughts relating to suicide, self-criticism and punishment items. The ROC curve analysis revealed moderate accuracy for the BDI-II's identification of depression in those with insomnia. The suggested BDI cutoff of $\geq 17$ had $81 \%$ sensitivity and $79 \%$ specificity. Use of the mild cutoff for depression $(\geq 14)$ had high sensitivity $(91 \%)$ but poor specificity $(66 \%)$.

Conclusion-Several items on the BDI-II might reflect sleep disturbance symptoms rather than depression per se. The recommended BDI-II cutoffs in this population have some support but a lower cutoff could result in an overclassification of depression in insomnia patients, a documented problem in the clinical literature. Understanding which items discriminate insomnia patients without depression may help address this nosological issue.

\section{Keywords}

Insomnia; Major Depressive Disorder; Insomnia Assessment; Depression Assessment

Contact Information: Colleen E. Carney, PhD, Work Address: 350 Victoria Street, JOR1037, Department of Psychology, Ryerson University, Toronto, Ontario, M5B 2K3 CANADA, Work Phone: 416-979-5000 x2177, E-mail: E-mail: ccarney@ ryerson.ca.

Publisher's Disclaimer: This is a PDF file of an unedited manuscript that has been accepted for publication. As a service to our customers we are providing this early version of the manuscript. The manuscript will undergo copyediting, typesetting, and review of the resulting proof before it is published in its final citable form. Please note that during the production process errors may be discovered which could affect the content, and all legal disclaimers that apply to the journal pertain. 
Major Depressive Disorder (MDD) and Primary Insomnia (PI) share daytime symptoms (e.g., concentration difficulties, reduced sleep, and fatigue) (Moul, et al, 2002), and insomnia is a highly prevalent complaint in those with Major Depressive Disorder (MDD) (Kupfer, et al, 1982). Approximately $60 \%$ of adults meeting criteria for MDD complain of insomnia, and between $10 \%$ and $20 \%$ of adults endorsing current insomnia display evidence of MDD (Ohayon, 2007). Furthermore, self-report measures employed to assess depression include symptoms that are essential features of primary insomnia. For example, The Beck Depression Inventory (BDI-II) (Beck, et al, 1996), includes the following symptoms that overlap with the Research Diagnostic Criteria (RDC) for insomnia (Edinger, et al, 2004): insomnia, mood disturbance, irritability, fatigue, impaired concentration, and motivation/anergia. These symptoms have been reported in clinical studies of insomnia patients, and thus, informed development of RDC for insomnia.

Due to concerns about overlapping symptomatology between medical conditions and depression, the validity of the BDI and the BDI-II has been assessed in various medical populations. The BDI-II has been assessed in: chronic pain patients (Poole, et al, 2006); hepatitis C patients (Golden, et al, 2007); adults post-acute coronary events (Di Benedetto, et al, 2006); African American primary care patients (Dutton, et al, 2004); traumatic brain injury patients (Rowland, et al, 2005); low income African American medical patients (Grothe, et al, 2005); medical outpatients (Viljoen, et al, 2003); stroke patients (Aben, et al, 2002); and in primary care medical patients (Arnau, et al, 2001). The findings of these studies generally support the use of the BDI-II in these populations. However, Golden, et al. (2007) found the BDI-II does not correspond well to a clinical diagnosis of Major Depressive disorder in Hepatitis C patients. The Cardiac Depression Scale was found to be more sensitive to the more subtle manifestation of depression than was the BDI-II in patients who are post-acute coronary syndrome (Di Benedetto, et al, 2006), and Poole et al. (2006) suggest scoring the BDI-II using a 2-factor approach in chronic pain patients. In summary, the empirical literature available thus far suggests support for the use of the BDI-II with most but not all medical populations.

As noted above, the assessment of depression in insomnia patients is similarly confounded by overlapping symptomatology across depressive and insomnia syndromes. As a result, it is difficult to ascertain whether elevated total scores or elevated responses on individual items of commonly used depression inventories reflect insomnia, depression with sleep symptoms, or comorbid insomnia and MDD. The purpose of the current study was to assess the accuracy of the BDI-II, one of the most commonly used depression measures, in detecting MDD in patients known to meet diagnostic criteria for insomnia. To date, the BDI has not been evaluated for use with insomnia patients.

\section{Methods}

\section{Participants}

Participants were a mixture of clinic-referred patients who presented as outpatients seeking insomnia treatment or as research volunteers for ongoing insomnia treatment trials at two academic medical centers (Duke University Medical Center, Durham, NC \& Rush Medical Center, Chicago, IL). Each site has an active insomnia clinic that services $\geq$ outpatients per calendar year as well as active NIH and/or industry sponsored insomnia research programs. The clinical patients at these sites include a mixture of physician and self-referred individuals, whereas research volunteers at these sites are often recruited via published English-language advertisements. Eligible participants were recruited into a larger insomnia diagnostic study $(\mathrm{N}=163)$. To be included in the study, participants must have been 18 years of age, fluent in English, mentally competent to provide informed consent, were not currently hospitalized, did not have significant cognitive impairment, and had not been previously evaluated by any of the diagnostic study clinicians at the recruitment site. Those with clinically significant sleep 
apnea were excluded using the following suggested criteria: 1) Apnea/Hypopnea Index (AHI) $\mathrm{I} \geq 15$, or $\mathrm{AHI} \geq 5$ with an Epworth Sleepiness Scale score $\geq 10$. This resulted in excluding 21 participants. Likewise, to exclude those with Periodic Limb Movement (PLM) Disorder, participants with a PLM arousal index $>5$ on either PSG night were excluded. This resulted in 2 exclusions. Those participants whose primary diagnosis was Restless Leg Syndrome or a Circadian Disorder (rather than an insomnia diagnosis) were excluded; no participants fit these criteria. This resulted in a final sample of 140 participants with insomnia. Table 1 provides a descriptive summary of the sample's demographic characteristics. Of these, 65\% (N=89) had primary insomnia, $27 \%(\mathrm{~N}=38)$ had insomnia due to a mental health condition, $4 \%(\mathrm{~N}=5)$ had insomnia due to a medical condition, and $4 \%(\mathrm{~N}=5)$ had dyssomnia NOS. About one-quarter of the sample $(\mathrm{N}=44,24.4 \%)$ endorsed use of hypnotic medications, and about one-fifth $(\mathrm{N}=38$, $21.1 \%$ ) endorsed antidepressant medication usage. Table 2 provides a descriptive summary of the sample with respect to comorbid medical conditions.

\section{Measures}

Mini-Mental Status Exam-The Folstein Mini-Mental Status Exam (Folstein, et al, 1975) was administered to all study participants following standard administration/scoring procedures. The MMSE was used to identify and exclude individuals with cognitive deficits that made them unable to give informed consent or fully participate in an interactive treatment process. For the purposes of this study, individuals who obtained an MMSE score $<24$ were excluded from participation.

Duke Structured Interview for Sleep Disorders (DSISD)—The DSISD was developed to assist in determining sleep disorders in accordance with both the DSM-IV and the recently updated International Classification of Sleep Disorders(ICSD-2) (American Academy of Sleep Medicine) sleep disorder nosologies. The DSISD is divided into 4 large modules respectively devoted to sleep disorders associated with insomnia complaints, sleep disorders associated with complaints of excessive daytime sleepiness-hypersomnia, circadian rhythm sleep disorders, and sleep disorders associated with parasomnias. Research conducted in our laboratory shows that the DSISD has acceptable reliability (kappa values ranging from .71 to .86 across DSM \& ICSD categories) and discriminant validity. Further, we found the instrument to be both easy to use and effective in discerning various types of sleep disorders (e.g., sleep apnea, restless legs syndrome, etc.).

Structured Interview for Psychiatric Disorders/SCID—Participants were screened using the SCID for Diagnostic and Statistical Manual of Mental Disorders Version IV-TR (DSM-IV-TR) Research Version (First, Spitzer, Gibbon \& Williams, 1997) to assess psychiatric status prior to enrollment, and for comorbid Axis I psychiatric conditions among those enrolled. Given the wide use of SCID methodology in various research applications over the past several decades, the current version of the SCID has a strong research legacy attesting to its reliability, validity, and utility for screening diagnosing study patients.

Polysomnography-All study participants completed two consecutive nights of polysomnographic (PSG) monitoring in the sleep laboratories of their respective study sites using Safiro ${ }^{\mathrm{TM}}$ recording devices (Compumedics USA, Inc., Fridley, MN). The Safiro ${ }^{\mathrm{TM}}$ is a 32-channel digital PSG recorder that allows sampling rates up to $512 \mathrm{~Hz}$. and accommodates both simple and complex recording montages. The PSG monitoring montage consisted of 2 channels of EEG $\left(\mathrm{C}_{3}-\mathrm{M}_{2}, \mathrm{Oz}-\mathrm{Cz}\right), 1$ chin EMG channel, 2 channels of EOG (left eye- $\mathrm{M}_{1}$, right eye- $\mathrm{M}_{2}$ ), 1 channel of airflow (nasal-oral thermistor), 2 channels of respiratory effort (thoracic and abdominal impedance), 1 channel of pulse oximetry (taken from the index finger), 2 channels of anterior tibialis EMG (right and left legs) and 1 channel of body position 
monitoring. Electrode attachments for these studies were performed in the sleep laboratory by trained technicians just prior to the respective participant's reported usual bedtime.

All PSG records acquired were scored on computer reader stations by experienced sleep technologists using standard scoring criteria (Rechtshaffen \& Kales, 1968). In addition, standard methods (Phillipson \& Remmers, 1989) were used to identify apneas and hypopneas present in the record and to calculate an apnea/hypopnea index - AHI (total number of apneas and hypopneas divided by total sleep time in hours). A desaturation index (i.e., number of $\mathrm{O}_{2}$ declines $\geq 3 \%$ from baseline per hour of sleep) was also calculated using oximetry data. Finally, standard criteria (American Sleep Disorders Association Task Force, 1992; Coleman, 1982) were used to identify periodic limb movements and periodic limb movement-related arousals, and a movement-arousal index - AI (total number of periodic limb movement-related arousals per hour of sleep) was calculated.

Sleep Logs-Subjective sleep estimates were obtained from most participants using a specially programmed hand-held computer. The electronic log consisted of a Palm Pilot $₫$-style personal data assistant (PDA) containing an interactive program that automates the collection of subjective sleep data. The program, developed by our lab using Satellite Forms software (@Thacker Network Technologies, Inc, Lacombe, Alberta), presented questions about each night's bedtime, sleep onset latency, number and length of nocturnal awakenings, time of final awaking, and rising time. Also, the program solicited respondents' ratings (made on a 10-point scale) of the quality of each night's sleep and how rested they felt upon arising. Participants were asked to record information in the electronic sleep log each morning upon arising throughout a two-week pre-interview assessment phase of the study. Estimates of total sleep time (TST), sleep onset latency (SOL), time spent awake after initially falling asleep or "wakefulness after sleep onset" (WASO), the percentage of time in bed spent sleeping or "sleep efficiency" (SE), a subjective Likert-scale rating of sleep quality and a subjective Likert scale rating of restedness upon awakening ratings were derived from sleep logs for use in this study.

Depression-All participants completed the Beck Depression Inventory, $2^{\text {nd }}$ edition (BDIII) (Beck, et al., 1996) as part of their study participation. The BDI-II has high internal consistency (alpha $=.91$ ), and an average test-retest reliability of .72 across 20 studies (Dozois $\&$ Covin, 2004). The BDI-II was designed to assess depression symptom severity, however, it is often used for diagnosis of depression due to its consistency with DSM-IV diagnostic criteria (Dozois et al, 2004). BDI-II scores range between 0 and 63, with categorical depression ratings of "minimal" (0-13), "mild" (14-19), "moderate" (20-28), and "severe" (29-63). Whereas some clinicians advocate using a cutoff of 14 to indicate the presence of mild depression symptoms, different cutoffs are used depending on the relative importance of sensitivity versus specificity in the population being assessed. A cutoff of $\leq 17$ was investigated in a study presented in the BDI-II manual (Beck, et al, 1996). In the clinical sample assessed ( $\mathrm{n}=127$ ) by Beck et al., a cutoff of 17 or greater had a $93 \%$ true-positive rate and a $18 \%$ false-positive rate. Beck et al. (1996) went on to recommend that researchers use ROC curves to evaluate cutoffs in the population of interest which is the approach taken by the present investigation.

Procedures-Participants were recruited via posted announcements on medical center bulletin boards and website, from volunteers for other studies in our medical center and through physician referrals. Study candidates demonstrating adequate cognitive abilities to complete study procedures (MMSE $\geq 24$ ) were enrolled in the study. A Structured Clinical Interview for DSM-IV disorders (SCID) (First, et al, 2002) was administered to study participants to determine the presence/absence of a MDD diagnosis. Participants completed the BDI-II, two weeks of sleep logs, and two nights of laboratory-administered polysomnography. The DSISD was then administered to determine DSM-IV-TR insomnia diagnosis. PSG and DSISD data were used to rule-out other sleep disorders, and those meeting diagnostic criteria for insomnia 
were classified as having insomnia: 1) without current MDD (I-ND), or 2) with current MDD (I-DEP). The presence of another primary comorbid psychiatric disorder on the SCID was recorded. Table 3 contains group psychiatric comorbidities. The vast majority of those without current depression did not have another primary psychiatric condition (88\%).

Analyses-An estimate of internal consistency (i.e., Cronbach's alpha) was calculated to assess the BDI-II's reliability in those with insomnia. Likewise, descriptive statistics (i.e., mean, range, standard deviation) were calculated for the two groups and the overall sample to provide an index of the scores produced by these subgroups. The mean BDI-II item responses for the two groups were compared using multivariate analysis of variance (MANOVA) and follow-up analysis of variance (ANOVAs). For items 16 and 18 there are "a" and "b" choices denoting opposite ends of symptom spectrums for sleep and appetite disturbance. For example, for question16, "b" responses denote insomnia and "a" responses denote hypersomnia. For question 18, "b" responses denote increased appetite and "a" responses denote decreased appetite. To evaluate both sets of responses, we assigned a zero to whichever item was not rated and entered the item into the MANOVA. For example, if a participant rated their sleep as $2 \mathrm{~b}$ (e.g., insomnia), we assigned a zero to the hypersomnia item. Likewise, if they rated their appetite as increased (i.e., 3b), we entered a zero for appetite decrease. This resulted in a MANOVA on 23 items. Lastly, accuracy rates for the previously mentioned clinical cutoffs (e.g., mild $\geq 14$ and clinically significant $\geq 17$ ) of the BDI-II were evaluated by calculating the area under the curve and conducting a Receiver operating characteristic (ROC) curve analysis.

\section{Results}

The internal consistency estimate (i.e., Cronbach's alpha) for the depressed and nondepressed groups were .888 and .817 , respectively. Cronbach's alpha was calculated using all 21 items.

\section{Group comparisons}

Demographic Variables-Table 1 provides a summary of the demographic characteristics of the study samples as well as group means and standard deviations for measures derived from sleep logs and the BDI-II. An ANOVA revealed that the I-Dep and I-ND groups did not differ on age, $F(1,138)=1.16, p=.284$. Chi Square analyses revealed that groups did not statistically differ on distribution of: 1 ) ethnicity/race [Chi Square $(1)=6.101, \mathrm{p}=.296$ ], or 2) gender [Chi Square $(1)=.001, \mathrm{p}=.984]$. Whereas the measures derived from sleep logs fell in the ranges expected for individuals with insomnia complaints, there were no statistically significant differences between the I-Dep and I-ND groups found in a MANOVA $[F(4,135)=1.11, p$ $=.357]$ on these indices.

Depression symptom severity comparisons-The depressed and not depressed groups were compared on their total BDI-II score (i.e., overall depression symptom severity). Because of the reported gender effects on depression inventories in the literature (Chavannes, et al, 2005; Dalgard, et al, 2006) we entered gender as a factor (Depression group X Gender). The ANOVA revealed a significant group effect for depression $[\mathrm{F}(1,137)=17.06, \mathrm{p}<.001]$, a significant effect for gender $[\mathrm{F}(1,137)=5.02, \mathrm{p}=.027]$, but no statistically significant interaction $[\mathrm{F}(1,137)=3.25, \mathrm{p}=.074]$. The I-DEP and I-ND groups were compared on individual BDI-II items to see which items differentiated the two groups. The MANOVA revealed a significant group effect for depression $[\mathrm{F}(23,114)=2.46, \mathrm{p}=.001]$, a significant effect for gender $[\mathrm{F}(23,114)=2.52, \mathrm{p}=.001]$, but no statistically significant interaction $[\mathrm{F}$ $(23,114)=1.61, p=.064]$. Because there was no significant interaction, and gender was not of interest in the study, only the group ANOVAs were conducted as a follow-up to the omnibus test. 
Table 4 contains the group means and follow-up ANOVA results for the individual items. The univariate ANOVAs revealed significant group (I-ND vs. I-DEP) differences on 14 of 23 possible items. Items that differentiated the I-ND and I-DEP groups included those related to depressed mood, pessimism, past failure, anhedonia, guilt, self-dislike, crying, agitation, indecision, worthlessness, energy, hypersomnia, and loss of appetite. In contrast, there were no statistically significant differences between the groups on items relating to: insomnia, irritability, suicidal ideation, increased appetite, decreased concentration, fatigue, libido thoughts of punishment and self-critical thoughts.

\section{Accuracy analysis}

The ROC curve is presented in Figure 1. The area under the curve for the BDI-II's identification of depression in those with insomnia was .838 , and was statistically significant at $\mathrm{p}<.001$. The $95 \%$ confidence interval was .75 to .92 ( $\mathrm{SE}=.043$ ). The suggested BDI cutoff of $\geq 17$ had $81 \%$ sensitivity and $79 \%$ specificity. The cutoff used for mild depression $(\geq 14)$ had $91 \%$ sensitivity and $66 \%$ specificity.

\section{Discussion}

The purpose of this study was to examine the properties of the BDI-II in a group characterized by significant symptom overlap with depression (i.e., insomnia patients). As expected, those with insomnia and depression had higher scores on the summed score of the BDI-II than those with insomnia alone. It is of note however that the insomnia group with no depression had scores in the "mild" symptom range for the BDI-II, rather than the no-symptom range (i.e., scores below 14). The accuracy analysis was generally supportive of the validity of the BDIII, and suggested the BDI-II has moderately high accuracy in identifying those insomnia patients with depression versus those insomnia patients without depression. The suggested cutoff score of 17 provides good sensitivity $(81 \%)$ and specificity (79\%) for detecting those with clinically significant depression. Although a lower cutoff (total score $\geq 14$ ) would produce greater sensitivity $(91 \%)$, the low specificity associated with this cutoff suggests it has limited value in identifying those who do not have depression (e.g., those with insomnia may be incorrectly classified as having depression). It would be interesting for a future study to investigate the sensitivity and specificity of the BDI-II in those without insomnia, as no study has systematically excluded insomnia patients. The fact that a cutoff of 17 provided good sensitivity in this comorbid group raises interest in how the cutoff would perform in those with depression only.

An item analysis revealed several items in which those with insomnia and those with insomnia and comorbid depression did not differ. The nondiscriminating symptoms were: insomnia, irritability, suicidal ideation, increased appetite, decreased concentration, fatigue, decreased libido, and self-critical and punishment-related thoughts. Thus, although there is support for the use of the BDI-II in those with insomnia, the degree of symptom overlap and the poor specificity with using a lower clinical cutoff suggest that some caution should be exercised. The fact that those with insomnia and no depression do not differ from those who are also depressed on reported symptom severity for 9 of the BDI-II items highlights the pronounced degree of impairment associated with insomnia. Indeed, chronic insomnia has been shown to rival MDD on several indices of quality of life (Katz \& McHorney, 2002) and it is the most common of health problems (Canals, et al, 1997). Thus, it is important for mental health providers not to underestimate the degree of impairment associated with insomnia.

Our subgroups of insomnia sufferers with and without depression showed similar propensity to endorse BDI-II insomnia items, suggesting that these two groups did not differ in regard to their subjective sleep disturbances. This impression is further corroborated by the lack of statistically significant group differences on prospective sleep log monitoring. This finding 
suggests that the sleep of those with depression is at least as poor as those who receive insomnia treatment (e.g., those with Primary Insomnia), and implies that those with comorbid depression and insomnia may be meritorious of separate insomnia treatment. Reinforcing this interpretation are findings from a number of other studies indicating that insomnia: (1) increases risk for subsequent depressive epsiodes (Chang, et al, 1997; Ford \& Kamerow, 1989; Perlis, et al 1997); (2) complicates the management of depressed patients (Buysse, et al, 1999; Thase, et al, 1996); and (3) often persists as a residual symptom after depression remits (Carney, et al, 2007). Furthermore, treatments that combine insomnia and depression therapies lead to better sleep and depression outcomes than do depression therapies used in isolation (Fava, et al, 2006; Manber, et al, 2008). Thus, our results, along with these other recent findings suggest that the insomnia occurring in the context of a depressive illness warrants separate treatment attention.

The low discriminability of the suicidal ideation item is potentially explained by the fact that those who would provide high ratings on the suicidal ideation item may be screened out of studies because of their suicide risk. However, the present finding is consistent with several other studies suggesting insomnia is a risk factor for suicide even after controlling for depression (Agargun, et al, 1997; Fawcett, et al, 1990; Sabo, et al, 1991). Certainly, more research is needed to investigate the link between suicide and this modifiable risk factor (i.e., chronic insomnia). It also seems noteworthy that daytime insomnia symptoms of fatigue, irritability and concentration problems did not differ in severity in our groups with and without clinical depression. This finding seems to validate the inclusion of such daytime symptoms as part of the Research Diagnostic Criteria for insomnia (Edinger, et al, 2004).

Our results did show, however, that there are some items that are quite useful for discriminating those insomnia patients with and without depression. Consistent with the DSM-IV-TR, symptoms such as sadness, pessimism, failures, guilt, crying, anhedonia, hypersomnia, and loss of appetite were depression symptoms that discriminated the groups. Clinicians should bear these symptoms in mind when interviewing a patient with an insomnia complaint. The absence of these core symptoms in an insomnia patient should alert the health care provider to the possibility that the patient may not have clinical depression, and instead is presenting with an insomnia syndrome.

The lack of specificity found for the mild BDI-II cutoff $\leq 14$ may be particularly important given that there is a general misunderstanding concerning the importance of insomnia and it's daytime sequelae (Haponik, et al, 1996). Evidence suggests that health care practitioners routinely and incorrectly utilize the presence of insomnia as "evidence" of depression. This approach to assessment does not consider the possibility of primary insomnia alone, with its overlapping depressive symptomatology, or the possibility of comorbid depression and primary insomnia. In a survey of over 3000 general practitioners, the most common symptom used to identify depression was the presence of a sleep complaint or insomnia (Krupinski \& Tiller, 2001). However, only 28\% of those diagnosed with MDD in the Krupinski \& Tiller study met DSM-IV criteria for this condition; the remaining patients were incorrectly diagnosed with MDD. Thus, if the mild depression cutoff is used in those with insomnia, it could result in misdiagnosis. Such a misdiagnosis is particularly troublesome in light of the fact that pharmacologic depression treatments may expose insomnia patients to unnecessary side effect profiles. Understanding that insomnia is a 24 -hour disorder with associated daytime symptoms is paramount to proper assessment of insomnia and discriminating those with primary insomnia from insomnia occurring with a depressive illness.

Decreased libido and increased appetite were also not different across insomnia sufferers with and without depression. Sleep, libido and appetite are all regulated in part by the HPA axis. This system is responsive to stress and has been implicated in depression and insomnia (Benca, 
2005). Perhaps the similar levels of severity across HPA-axis regulated symptoms in those with and without depression relates to a shared sustaining physiologic pathway (e.g., HPA axis dysregulation).

The lack of statistically significant differences between groups on BDI-II items concerning thoughts of punishment and self-critical thoughts are perhaps less intuitive findings. One possible explanation is that having a negative thinking style may predispose some to suffer from insomnia. The Cognitive Therapy component of both CBT for insomnia and CBT for depression would presumably target such beliefs for modification; however, this may be important to test. Also, perhaps a negative cognitive style may be a risk factor for depression that is present in those with insomnia. Future studies could test the significance of this thinking style in both insomnia and depression.

It is important to consider the findings of this study in light of several possible limitations. This study may be limited by the modest size of the depressed group. Although the overall sample size was moderately large $(\mathrm{N}=140)$, it is possible that a larger sample size could reveal further differences between the groups. The large $\mathrm{F}$ values for some of the nonsignificant results would suggest that symptoms of concentration and fatigue could potentially reach statistical significance if there was an even larger sample size. In addition, a 4-point rating scale is a limited range and perhaps a scale with a larger range of possible values would yield group differences. Lastly, there were a number of comorbid conditions that could have influenced the results. Nonetheless, these findings are consistent with the clinical practice studies mentioned above.

This study highlights some of the key problems with assessing both depression and insomnia. Insomnia and MDD have overlapping sleep specific and daytime symptoms and symptom severity. Understanding the daytime symptoms is as important for assessment as is understanding the limitations of particular assessment tools when assessing particular patient groups. The current study showed that people with insomnia alone did not differ from those with a comorbid depression diagnosis in the severity of particular symptoms. This finding underscores the severity of insomnia and the lack of support for the idea that insomnia is an insignificant disorder. Finally, it should be noted that the current study provided evidence for the usefulness of the BDI-II for detecting clinically significant depression in those with insomnia. However, the use of a mild depression symptom cutoff $\leq 14$ seemingly results in a bias towards diagnosing depression in the absence of an actual clinical depression.

\section{Acknowledgements}

This research was supported by a Pickwick Fellowship Award (Dr. Carney) from the National Sleep Foundation and by the National Institute of Mental Health Grant \# R01, MH067057 (Dr. Edinger).

\section{References}

Aben I, Verhey F, Lousberg R, Lodder J, Honig A. Validity of the Beck Depression Inventory, Hospital Anxiety and Depression Scale, SCL-90 and Hamilton Depression Rating Scale as screening instruments for depression in stroke patients. Psychosomatics: Journal of Consultation Liaison Psychiatry 2002;43:386-393.

Agargun MY, Kara H, Solmaz M. Sleep disturbances and suicidal behavior in patients with major depression. Journal of Clinical Psychiatry 1997;58:249-251. [PubMed: 9228889]

Hauri, PJ, Chairman. American Academy of Sleep Medicine. International classification of sleep disorders-second edition (ICSD-2). International Classification of Sleep Disorders Steering Committee; Chicago. 2005.

American Sleep Disorders Association Task Force. EEG arousals: Scoring rules and examples. C Guilleminault, chairman. Sleep 1992;15:173-184. [PubMed: 11032543] 
Arnau RC, Meagher MW, Norris MP, Bramson R. Psychometric evaluation of the Beck Depression Inventory-II with primary care medical patients. Health Psychology 2001;20:112-119. [PubMed: 11315728]

Beck, AT.; Steer, RA.; Brown, GK. Manual for the Beck Depression Inventory, Second Edition (BDIII). San Antonio, TX: The Psychological Association; 1996.

Benca, RM. Mood Disorders. In: Kryger, MA.; Roth, T.; Dement, WC., editors. Principles and practice of sleep medicine. Philadelphia: Elsevier Saunders; 2005. p. 1311-1326.

Buysse DJ, Tu XM, Cherry CR, Begley AE, Kowalski J, Kupfer DJ, Frank E. Pretreatment REM sleep and subjective sleep quality distinguish depressed psychotherapy remitters and nonremitters. Biological Psychiatry 1999;45:205-213. [PubMed: 9951568]

Canals J, Domenech E, Carbajo G, Blade J. Prevalence of DSM-III-R and ICD-10 psychiatric disorders in a Spanish population of 18 year olds. Acta Psychiatrica Scandinavica 1997;96:287-294. [PubMed: 9350958]

Carney CE, Edinger JD, Manber R, Garson CS, Segal ZV. Beliefs about sleep in disorders characterized by sleep and mood disturbance. Journal of Psychosomatic Research 2007;62:179-188. [PubMed: 17270576]

Carney CE, Segal ZV, Edinger JD, Krystal AD. A comparison of rates of residual insomnia symptoms following pharmacotherapy or cognitive behavioral therapy for major depression. The Journal of Clinical Psychiatry 2007;68:254-260. [PubMed: 17335324]

Chang PP, Ford DE, Mead LA, Cooper-Patrick L, Klag MJ. Insomnia in young men and subsequent depression. The Johns Hopkins Precursors Study American Journal of Epidemiology 1997;146:105114.

Chavannes NH, Huibers MJ, Schermer TR, Hendriks A, van Weel C, Wouters EF, van Schayck CP. Associations of depressive symptoms with gender, body mass index and dyspnea in primary care COPD patients. Family Practice 2005;22:604-607. [PubMed: 16024555]

Coleman, R. Periodic movements in sleep (nocturnal myoclonus) and restless legs syndrome. In: Guilleminault, C., editor. Sleeping and waking disorders: Indications and techniques. Menlo Park: Addison-Wesley; 1982. p. 265-295.

Dalgard O, Dowrick C, Lehtinen V, Vazquez-Barquero JL, Casey P, Wilkinson G, Ayuso-Mateos JL, Page H, Dunn G. Negative life events, social support and gender difference in depression: a multinational community survey with data from the ODIN study. Social Psychiatry and Psychiatric Epidemiology 2006;41:444-451. [PubMed: 16572275]

Di Benedetto M, Lindner H, Hare DL, Kent S. Depression following acute coronary syndromes: A comparison between the Cardiac Depression Scale and the Beck Depression Inventory II. Journal of Psychosomatic Research 2006;60:13-20. [PubMed: 16380305]

Dozois, DJA.; Covin, R. The Beck Depression Inventory-II (BDI-II), Beck Hopelessness Scale (BHS), and Beck Scale for Suicide Ideation (BSS). In: Hersen, M.; Hilsenroth, MJ.; Segal, DL., editors. Comprehensive Handbook of Psychological Assessment: Personality assessment. New York: John Wiley \& Sons, Inc; 2004. p. 50-69.

Dutton GR, Grothe KB, Jones GN, Whitehead D, Kendra KJ, Brantley PJ. Use of the Beck Depression Inventory-II with African American primary care patients. General Hospital Psychiatry 2004;26:437-442. [PubMed: 15567209]

Edinger JD, Bonnet M, Bootzin RR, Doghramji K, Dorsey CM, Espie CA, Jamieson AO, McCall VW, Morin CM, Stepanski EJ. Derivation of research diagnostic criteria for insomnia: Report on an American Academy of Sleep Medicine work group. Sleep 2004;27:1567-1596. [PubMed: 15683149]

Fava M, McCall VW, Krystal AD, Wessel T, Rubens R, Caron J, Amato D, Roth T. Eszopiclone coadministered with fluoxetine in patients with insomnia co-existing with Major Depressive Disorder. Biological Psychiatry 2006;59:1052-1060. [PubMed: 16581036]

Fawcett J, Scheftner WA, Fogg L, Clark DA, Young MA, Hedeker D, Gibbons R. Time-related predictors of suicide in Major Affective Disorder. American Journal of Psychiatry 1990;147:1189-1194. [PubMed: 2104515]

Fichten, CS.; Libman, E.; Bailes, S.; Alapin, I. Characteristics of older adults with insomnia. In: Lichstein, KL.; Morin, CM., editors. Treatment of late-life insomnia. Thousand Oaks, CA: Sage Publications; 2000. p. 37-79. 
First, MB.; Spitzer, RL.; Gibbon, M.; Williams, JBW. Structured Clinical Interview for DSM-IV-TR Axis I Disorders, Research Version, Patient Edition (SCID-I/P). New York: Biometrics Research, New York State Psychiatric Institute; 2002.

Folstein MF, Folstein SE, McHugh PR. Mini Mental State: A practical method for grading the cognitive state of patients for the clinician. Journal of Psychiatric Research 1975;12:189-198. [PubMed: 1202204]

Ford D, Kamerow D. Epidemiologic study of sleep disturbances in psychiatric disorders. JAMA 1989;262:1479-1484. [PubMed: 2769898]

Golden J, Conroy RM, O'Dwyer AM. Reliability and validity of the Hospital Anxiety and Depression Scale and the Beck Depression Inventory (Full and FastScreen scales) in detecting depression in persons with hepatitis C. Journal of Affective Disorders 2007;100:265-269. [PubMed: 17156850]

Grothe KB, Dutton GR, Jones GN, Bodenlos J, Ancona M, Brantley PJ. Validation of the Beck Depression Inventory-II in a Low-Income African American Sample of Medical Outpatients. Psychological Assessment 2005;17:110-114. [PubMed: 15769232]

Haponik E, Frye A, Richards B, Wymer A, Hinds A. Sleep history is neglected diagnostic information. Journal of General Internal Medicine 1996;11:759-761. [PubMed: 9016425]

Hatoum HT, Kong SX, Kania CM, Wong JM, Mendelson WB. Insomnia, health-related quality of life and healthcare resource consumption: A study of managed care organisation enrollees. Pharmacoeconomics 1998;14:629-637. [PubMed: 10346415]

Katz DA, McHorney CA. The relationship between insomnia and health-related quality of life in patients with chronic illness. The Journal of Family Practice 2002;51:229-235. [PubMed: 11978233]

Krupinski J, Tiller JW. The identification and treatment of depression by general practitioners. Australian and New Zealand Journal of Psychiatry 2001;35:827-832. [PubMed: 11990894]

Kupfer, DJ.; Reynolds, CI.; Ulrich, RF.; Shaw, DH.; Coble, PA. EEG sleep, depression and aging. In: Bartus, RI., editor. Neurobiology of Aging: Experimental Clinical Research. Fayettesville: Ankho International; 1982. p. 351-360.

Manber R, Edinger JD, Gress JL, San Pedro-Salcedo MG, Kuo TF, Kalista T. I Cognitive behavioral therapy for insomnia enhances depression outcome in patients with comorbid major depressive disorder and insomnia. Sleep 2008;31:489-495. [PubMed: 18457236]

Mendelson WB, Garnett D, Gillin JC, Weingartner H. The experience of insomnia and daytime and nighttime functioning. Psychiatry Research 1984;12:235-250. [PubMed: 6593755]

Moul DE, Nofzinger EA, Pilkonis PA, Houck PR, Mielwald JM, Buysse DJ. Symptom reports in severe chronic insomnia. Journal of Sleep Research 2002a;25:548-558.

Moul DE, Nofzinger EA, Pilkonis PA, Houck PR, Miewald JM, Buysse DJ. Symptom reports in severe chronic insomnia. Sleep 2002b;25:548-558.

Ohayon MM. Insomnia: A ticking clock for depression? Journal of Psychiatric Research 2007;41:893894. [PubMed: 17709046]

Perlis M, Giles DE, Buysse DJ, Tu X, Kupfer DJ. Self-reported sleep disturbance as a prodromal symptom in recurrent depression. Journal of Affective Disorders 1997;42:209-212. [PubMed: 9105962]

Phillipson EA, Remmers JE. American Thoracic society Consensus conference on Indications and Standards for Cardiopulmonary Sleep Studies. American Review of Respiratory Disease 1989;139:559-568. [PubMed: 2643907]

Poole H, Bramwell R, Murphy P. Factor Structure of the Beck Depression Inventory-II Patients with Chronic Pain. Clinical Journal of Pain 2006;22:790-798. [PubMed: 17057561]

Rechtshaffen, A.; Kales, A. A manual of standardized terminology, techniques, and scoring systems of sleep stages of human subjects. Los Angeles: UCLA Brain Information Service/Brain Research Institute; 1968.

Rowland SM, Lam CS, Leahy B. Use of the Beck Depression Inventory-II (BDI-II) with persons with traumatic brain injury: Analysis of factorial structure. Brain Injury 2005;19:77-83. [PubMed: 15841751]

Sabo E, Reynolds CF, Kupfer DJ, Berman SR. Sleep, depression, and suicide. Psychiatry Research 1991;36:265-77. [PubMed: 2062968]

Thase ME, Simons AD, Reynolds CF III. Abnormal EEG sleep profiles in major depression: Association with response to CBT. Archives of General Psychiatry 1996;53:99-108. [PubMed: 8629894] 
Viljoen JL, Iverson GL, Griffiths S, Woodward TS. Factor structure of the Beck Depression InventoryII in a medical outpatient sample. Journal of Clinical Psychology in Medical Settings 2003;10:289_ 291. 


\section{ROC Curve}

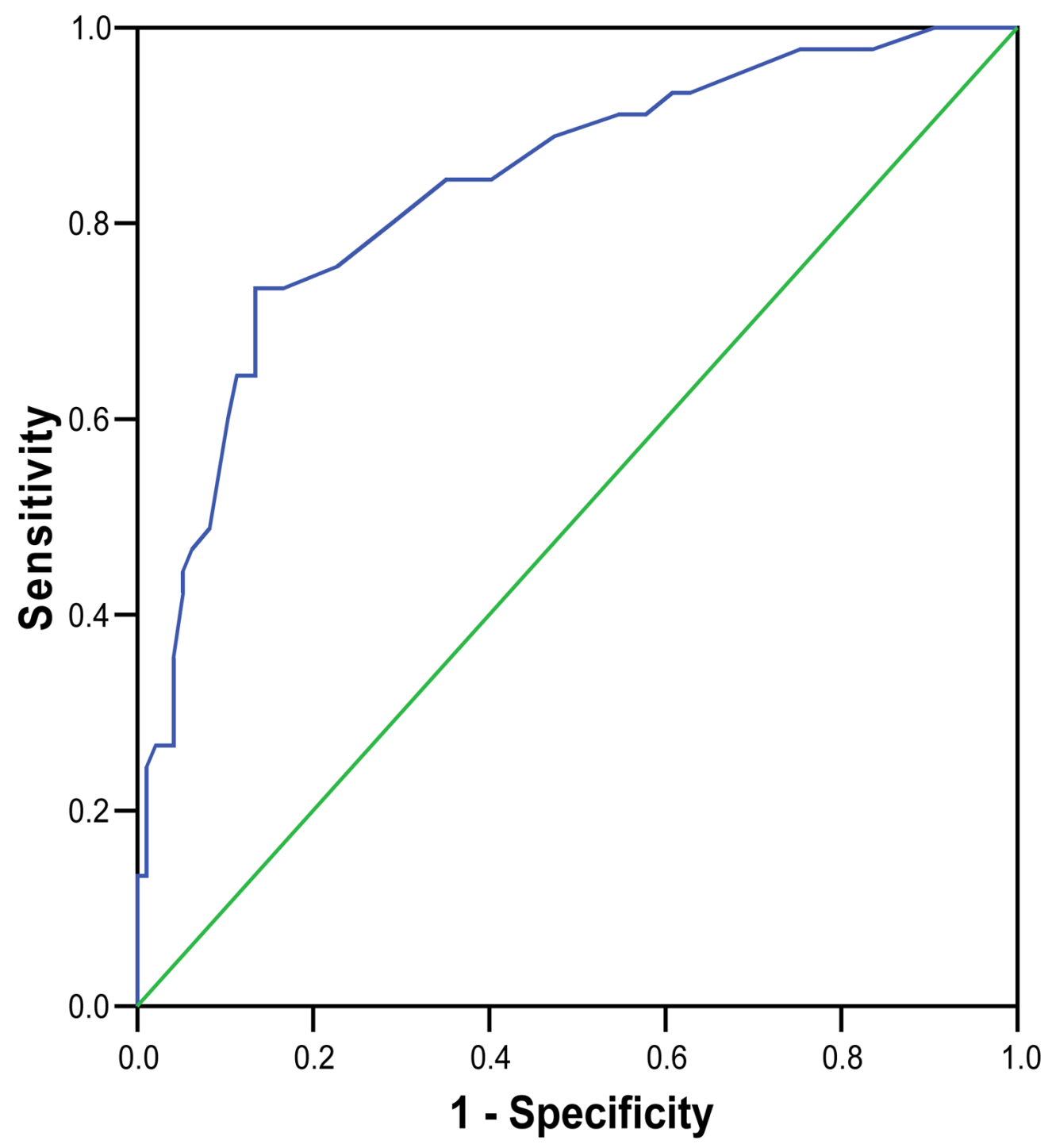

Diagonal segments are produced by ties.

Figure 1.

Receiver Operating Characteristic Curve 
Table 1

Demographic, Mood and Sleep Characteristics

\begin{tabular}{|c|c|c|c|}
\hline Variable & Nondepressed & Depressed & Total sample \\
\hline \multicolumn{4}{|l|}{$\underline{\text { Gender }}$} \\
\hline Female & $74 \%$ & $74 \%$ & $74 \%$ \\
\hline \multicolumn{4}{|l|}{$\underline{\text { Age }}$} \\
\hline Mean & $48.2(13.4)$ & $46.4(10.8)$ & $47.8(12.8)$ \\
\hline Range & 24-81 years old & 24-77 years old & 24-81 years old \\
\hline \multicolumn{4}{|l|}{$\underline{\text { Race/Ethnicity }}$} \\
\hline Caucasian & $48 \%$ & $67 \%$ & $53 \%$ \\
\hline African American & $41 \%$ & $23 \%$ & $36 \%$ \\
\hline Asian & $4 \%$ & 0 & $3 \%$ \\
\hline Other & $7 \%$ & $10 \%$ & $8 \%$ \\
\hline \multicolumn{4}{|l|}{$\underline{\text { BDI-II }}$} \\
\hline Mean (SD) & $12.04(9.65)$ & $22.00(8.59)$ & $14.07(10.23)$ \\
\hline \multicolumn{4}{|l|}{ Sleep Log } \\
\hline Mean SOL & $45.97(39.12)$ & $55.09(29.93)$ & $47.84(37.45)$ \\
\hline Mean WASO & $78.19(43.27)$ & $94.49(50.16)$ & $81.53(44.93)$ \\
\hline Mean TST & $357.64(71.49)$ & $358.88(68.61)$ & $357.89(70.50)$ \\
\hline Mean SE & $74.19 \%(11.29)$ & $70.80 \%(13.00)$ & $73.50 \%(11.66)$ \\
\hline
\end{tabular}

SOL=Sleep Onset Latency; WASO=Wake After Sleep Onset; TST=Total Sleep Time; SE=Sleep Efficiency; SD=Standard Deviation 
Table 2

Medical Conditions self-reported by Study Participants

\begin{tabular}{|c|c|c|}
\hline Medical Condition & $\begin{array}{l}\text { Number of I-ND Participants endorsing } \\
\text { Condition ( } \% \text { of group) }\end{array}$ & $\begin{array}{l}\text { Number of I-DEP Participants endorsing } \\
\text { Condition ( } \% \text { of group) }\end{array}$ \\
\hline Heart Disease & $16(17 \%)$ & $8(17 \%)$ \\
\hline Pulmonary Disease & $11(12 \%)$ & $5(11 \%)$ \\
\hline Gastrointestinal Disorder & $14(15 \%)$ & $11(24 \%)$ \\
\hline Neurologic Disorder & $1(1 \%)$ & $3(7 \%)$ \\
\hline Head Trauma History & $0(0 \%)$ & $1(2 \%)$ \\
\hline Chronic Pain Disorder & $34(36 \%)$ & $21(46 \%)$ \\
\hline Endocrine Disorder & $6(6 \%)$ & $6(13 \%)$ \\
\hline Metabolic Disorder & $3(3 \%)$ & $5(11 \%)$ \\
\hline Kidney Disease & $1(1 \%)$ & $0(0 \%)$ \\
\hline Autoimmune Disorder & $1(1 \%)$ & $3(7 \%)$ \\
\hline Cancer & $0(0 \%)$ & $2(4 \%)$ \\
\hline HIV/AIDS & $4(4 \%)$ & $1(2 \%)$ \\
\hline Chronic Headaches & $12(13 \%)$ & $10(22 \%)$ \\
\hline Other & $5(5 \%)$ & $1(2 \%)$ \\
\hline
\end{tabular}

Note. Participants could have multiple medical comorbidities. 
Table 3

Distribution of Sample by Psychiatric Comorbidities (DSM-IV as determined by SCID)

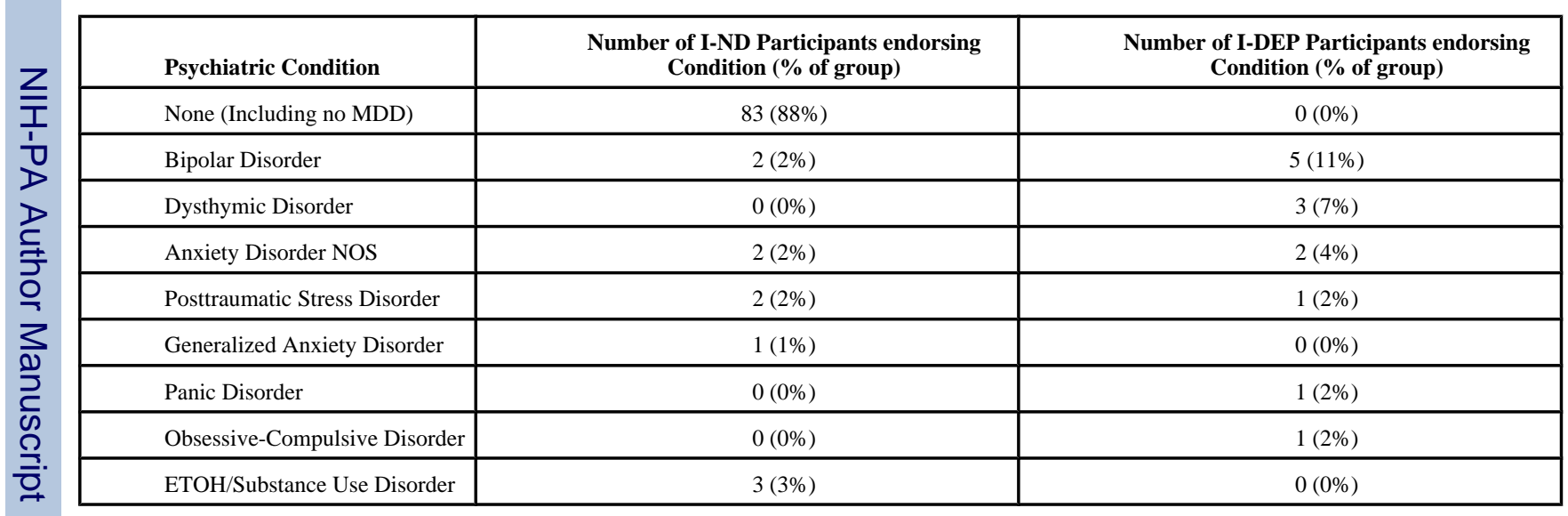


Table 4

Group item means, Item Total Correlations, and ANOVA F-test results

\begin{tabular}{|c|c|c|c|c|}
\hline \multirow[b]{2}{*}{ BDI-II Item } & & \multicolumn{2}{|c|}{ Group } & \multirow[t]{2}{*}{ F results and effect size $\left(\right.$ eta $\left.^{2}\right)$} \\
\hline & & Depressed & Non-Depressed & \\
\hline Sadness & $\begin{array}{l}\text { Mean } \\
\text { SD }\end{array}$ & $\begin{array}{l}1.06 \\
0.76\end{array}$ & $\begin{array}{l}0.33 \\
0.52\end{array}$ & $\begin{array}{l}\mathrm{F}(1,136)=16.46, \mathrm{p}<.001^{*} \\
\mathrm{eta}^{2}=.30\end{array}$ \\
\hline Pessimism & $\begin{array}{l}\text { Mean } \\
\text { SD }\end{array}$ & $\begin{array}{l}1.19 \\
1.03\end{array}$ & $\begin{array}{l}0.42 \\
0.58\end{array}$ & $\begin{array}{l}\mathrm{F}(1,136)=10.90, \mathrm{p}=.001^{*} \\
\mathrm{eta}^{2}=.22\end{array}$ \\
\hline Past Failure & $\begin{array}{l}\text { Mean } \\
\text { SD }\end{array}$ & $\begin{array}{l}1.28 \\
1.02\end{array}$ & $\begin{array}{l}0.48 \\
0.68\end{array}$ & $\begin{array}{l}\mathrm{F}(1,136)=10.37, \mathrm{p}=.0022^{*} \\
\mathrm{eta}^{2}=.19\end{array}$ \\
\hline Loss of Pleasure & $\begin{array}{l}\text { Mean } \\
\text { SD }\end{array}$ & $\begin{array}{l}1.41 \\
0.71\end{array}$ & $\begin{array}{l}0.69 \\
.078\end{array}$ & $\begin{array}{l}\mathrm{F}(1,136)=10.21, \mathrm{p}=.002^{*} \\
\mathrm{eta}^{2}=.18\end{array}$ \\
\hline Guilty Feelings & $\begin{array}{l}\text { Mean } \\
\text { SD }\end{array}$ & $\begin{array}{l}0.97 \\
0.74\end{array}$ & $\begin{array}{l}0.49 \\
0.64\end{array}$ & $\begin{array}{l}\mathrm{F}(1,136)=8.64, \mathrm{p}=.004^{*} \\
\text { eta }^{2}=.12\end{array}$ \\
\hline Punishment & $\begin{array}{l}\text { Mean } \\
\text { SD }\end{array}$ & $\begin{array}{l}0.59 \\
1.04\end{array}$ & $\begin{array}{l}0.28 \\
0.71\end{array}$ & $\begin{array}{l}\mathrm{F}(1,136)=0.34, \mathrm{p}=.563, \text { eta }^{2} \\
=.04\end{array}$ \\
\hline Self-Dislike & $\begin{array}{l}\text { Mean } \\
\text { SD }\end{array}$ & $\begin{array}{l}1.34 \\
094\end{array}$ & $\begin{array}{l}0.58 \\
0.85\end{array}$ & $\begin{array}{l}\mathrm{F}(1,136)=11.21, \mathrm{p}<.001^{*} \\
\text { eta }^{2}=.15\end{array}$ \\
\hline Self-Critical & $\begin{array}{l}\text { Mean } \\
\text { SD }\end{array}$ & $\begin{array}{l}1.00 \\
0.92\end{array}$ & $\begin{array}{l}0.50 \\
0.76\end{array}$ & $\begin{array}{l}\mathrm{F}(1,136)=1.85, \mathrm{p}=.176, \text { eta }^{2} \\
=.09\end{array}$ \\
\hline Suicidal Thoughts & $\begin{array}{l}\text { Mean } \\
\text { SD }\end{array}$ & $\begin{array}{l}0.25 \\
0.44\end{array}$ & $\begin{array}{l}0.10 \\
0.31\end{array}$ & $\begin{array}{l}\mathrm{F}(1,136)=0.96, \mathrm{p}=.328, \text { eta }^{2} \\
=.11\end{array}$ \\
\hline Crying & $\begin{array}{l}\text { Mean } \\
\text { SD }\end{array}$ & $\begin{array}{l}1.41 \\
1.34\end{array}$ & $\begin{array}{l}0.35 \\
0.77\end{array}$ & $\begin{array}{l}\mathrm{F}(1,136)=6.35, \mathrm{p}=.013^{*} \\
\mathrm{eta}^{2}=.22\end{array}$ \\
\hline Agitation & $\begin{array}{l}\text { Mean } \\
\text { SD }\end{array}$ & $\begin{array}{l}1.09 \\
0.78\end{array}$ & $\begin{array}{l}0.50 \\
0.68\end{array}$ & $\begin{array}{l}\mathrm{F}(1,136)=10.07, \mathrm{p}=.002^{*} \\
\text { eta }^{2}=.17\end{array}$ \\
\hline Loss of Interest & $\begin{array}{l}\text { Mean } \\
\text { SD }\end{array}$ & $\begin{array}{l}1.41 \\
0.95\end{array}$ & $\begin{array}{l}0.43 \\
0.68\end{array}$ & $\begin{array}{l}\mathrm{F}(1,136)=15.00, \mathrm{p}<.001^{*} \\
\mathrm{eta}^{2}=.25\end{array}$ \\
\hline Indecisiveness & $\begin{array}{l}\text { Mean } \\
\text { SD }\end{array}$ & $\begin{array}{l}1.28 \\
0.99\end{array}$ & $\begin{array}{l}0.60 \\
0.81\end{array}$ & $\begin{array}{l}\mathrm{F}(1,136)=7.27, \mathrm{p}=.008^{*} \\
\text { eta }^{2}=.14\end{array}$ \\
\hline Worthlessness & $\begin{array}{l}\text { Mean } \\
\text { SD }\end{array}$ & $\begin{array}{l}0.94 \\
0.98\end{array}$ & $\begin{array}{l}0.22 \\
0.54\end{array}$ & $\begin{array}{l}\mathrm{F}(1,136)=10.38, \mathrm{p}=.002^{*} \\
\mathrm{eta}^{2}=.22\end{array}$ \\
\hline Loss of Energy & $\begin{array}{l}\text { Mean } \\
\text { SD }\end{array}$ & $\begin{array}{l}1.47 \\
0.72\end{array}$ & $\begin{array}{l}0.88 \\
0.69\end{array}$ & $\begin{array}{l}\mathrm{F}(1,136)=6.82, \mathrm{p}=.010^{*} \\
\mathrm{eta}^{2}=.09\end{array}$ \\
\hline
\end{tabular}




\begin{tabular}{|c|c|c|c|c|}
\hline \multirow[b]{2}{*}{ BDI-II Item } & & \multicolumn{2}{|c|}{ Group } & \multirow[t]{2}{*}{ F results and effect size $\left(\mathrm{eta}^{2}\right)$} \\
\hline & & Depressed & Non-Depressed & \\
\hline Hypersomnia & $\begin{array}{l}\text { Mean } \\
\text { SD }\end{array}$ & $\begin{array}{l}0.19 \\
0.39\end{array}$ & $\begin{array}{l}0.06 \\
0.23\end{array}$ & $\begin{array}{l}\mathrm{F}(1,136)=7.52, \mathrm{p}=.007^{*} \\
\text { eta }^{2}=.10\end{array}$ \\
\hline Insomnia & $\begin{array}{l}\text { Mean } \\
\text { SD }\end{array}$ & $\begin{array}{l}1.38 \\
1.10\end{array}$ & $\begin{array}{l}1.48 \\
1.15\end{array}$ & $\begin{array}{l}\mathrm{F}(1,136)=0.64, \mathrm{p}=.423, \text { eta }^{2} \\
=.001\end{array}$ \\
\hline Irritability & $\begin{array}{l}\text { Mean } \\
\text { SD }\end{array}$ & $\begin{array}{l}0.81 \\
0.78\end{array}$ & $\begin{array}{l}0.51 \\
0.70\end{array}$ & $\begin{array}{l}\mathrm{F}(1,136)=1.07, \mathrm{p}=.303, \text { eta }^{2} \\
=.13\end{array}$ \\
\hline Decreased Appetite & $\begin{array}{l}\text { Mean } \\
\text { SD }\end{array}$ & $\begin{array}{l}0.59 \\
0.95\end{array}$ & $\begin{array}{l}0.22 \\
0.49\end{array}$ & $\begin{array}{l}\mathrm{F}(1,136)=9.17, \mathrm{p}=.003^{*} \\
\text { eta }^{2}=.08\end{array}$ \\
\hline Increased Appetite & $\begin{array}{l}\text { Mean } \\
\text { SD }\end{array}$ & $\begin{array}{l}0.62 \\
1.01\end{array}$ & $\begin{array}{l}0.31 \\
0.67\end{array}$ & $\begin{array}{l}F(1,136)=0.48, p=.488, \text { eta }^{2} \\
=.03\end{array}$ \\
\hline Concentration & $\begin{array}{l}\text { Mean } \\
\text { SD }\end{array}$ & $\begin{array}{l}1.22 \\
0.66\end{array}$ & $\begin{array}{l}0.80 \\
0.78\end{array}$ & $\begin{array}{l}\mathrm{F}(1,136)=3.32, \mathrm{p}=.071, \text { eta }^{2} \\
=.05\end{array}$ \\
\hline Fatigue & $\begin{array}{l}\text { Mean } \\
\text { SD }\end{array}$ & $\begin{array}{l}1.44 \\
0.98\end{array}$ & $\begin{array}{l}0.91 \\
0.81\end{array}$ & $\begin{array}{l}\mathrm{F}(1,136)=3.607, \mathrm{p}=.060 \\
\text { eta }^{2}=.05\end{array}$ \\
\hline Decreased Libido & $\begin{array}{l}\text { Mean } \\
\text { SD }\end{array}$ & $\begin{array}{l}1.13 \\
1.19\end{array}$ & $\begin{array}{l}0.76 \\
0.90\end{array}$ & $\begin{array}{l}\mathrm{F}(1,136)=.05, \mathrm{p}=.819, \text { eta }^{2}= \\
01\end{array}$ \\
\hline
\end{tabular}

sig. at alpha $=.05 ;$ effect size estimates $=$ eta squared $\left(\mathrm{eta}^{2}\right)$ 